Submission ID: 43900

\title{
Adaptive Forecasting of Work-Over Technique and Enhanced Oil Recovery
} Method Efficiency

E.N. Taraskin* (LUKOIL-Engineering LLC - PermNIPIneft), S.O. Ursegov (Skolkovo Institute of Science and Technology), A.Z. Zakharian (Cervart Ltd)

\section{SUMMARY}

The development of modern drilling, production, and geophysical measurements outruns existing technologies for analyzing the information obtained from these studies and for forecasting the reservoir development process based on this analysis. This paper suggests one possible way to correct such situation. The developed approach is based on the adaptive geological-hydrodynamic model of oil fields or reservoirs. Its fundamental difference from the traditional deterministic approach lies in the fact that the adaptive model never changes the initial data, but allows one to change its mathematical apparatus, adjusting to these data. As the mathematical apparatus in the adaptive model, the integrated fuzzy logic schemes are used. The adaptive model is not simplistic, it is complex and requires the same run time as the deterministic model. The novelty of this paper is that an alternative approach to geological-hydrodynamic modeling is suggested that is more adequate to the available information. The constructed adaptive models have shown their capabilities for the conditions of many oil fields and reservoirs. The results of predicting the efficiency of work-over techniques and methods of enhanced oil recovery in those fields and reservoirs based on the new adaptive approach are presented and analyzed in this paper. 
Адаптивное прогнозирование эффективности геолого-технических мероприятий и методов увеличения нефтеотдачи пластов

Тараскин Е.Н.* (филиал ООО «ЛУКОЙЛ-Инжиниринг» «ПермНИПИнефть» в г. Перми), Урсегов С.О. (АНО ВО «Сколковский институт науки и технологий»), Захарян А.З. (ООО «Черварт»)

Развитие современных технологий бурения, нефтегазодобычи и геофизических измерений опережает существующие технологии анализа полученной информации и прогнозирования состояния разработки месторождений и залежей на основании этого анализа. Нередко результаты дорогостоящих исследований практически не используются и ждут своего часа. Один их возможных путей для того, чтобы исправить сложившуюся ситуацию, заключается в создании адаптивных геолого-гидродинамических моделей. Принципиальным отличием этих моделей от детерминированных [1] является то, что адаптивные модели никогда не меняют исходные данные, но позволяют изменять свой математический аппарат, подстраиваясь под эти данные. Новизна работы состоит в том, что предложен альтернативный подход к геологогидродинамическому моделированию, более адекватный имеющейся геолого-промысловой информации и актуальным практическим задачам.

В отличие от традиционных адаптивных моделей, которые прогнозируют добычу нефти на основе характеристик вытеснения [2], новый адаптивный подход (НАП) интегрирует всю известную информацию о рассматриваемом объекте в виде его полномасштабной трехмерной модели. Причем объем исходной информации для построения адаптивной модели сопоставим с объемом исходной информации для построения детерминированной модели. Новая адаптивная модель включает в себя геологический и гидродинамический компоненты. Однако строятся они по другим принципам нежели их детерминированные аналоги. С использованием адаптивной гидродинамической модели возможно прогнозирование не только уровней нефтедобычи, но и эффективности проведения различных геолого-технических мероприятий (ГТМ) и методов увеличения нефтеотдачи пластов (МУН). В качестве математического аппарата НАП использует методы машинного обучения, в частности интегральные нечеткологические схемы, которые способны порождать новые ситуации [3].

В работе рассмотрены результаты применения НАП для двух крупных объектов с высоковязкими нефтями - пермо-карбоновой залежи Усинского месторождения и месторождения Северные Бузачи. Пермо-карбоновая залежь Усинского месторождения, размещается в трехсотметровой карбонатной толще, в которой имеется несколько внутри формационных размывов, многочисленные биогермные тела, а также достаточно густая сеть разломов и линеаментов. Наличие зон активной вертикальной трещиноватости совместно с маломощной глинистой покрышкой привело к потере нефтью залежи легких и летучих компонентов и приобретению аномальной вязкости в среднем от 700 до 1000 мПа*с. В качестве альтернативы имеющимся детерминированным моделям залежи при помощи НАП были созданы ее адаптивные геологическая и гидродинамическая модели.

В основе любой гидродинамической модели (детерминированной или адаптивной) находится геологическая модель. Обычно создают детерминированные геологические модели, которые содержат сотни миллионов ячеек и хотят перейти к миллиардам. Адаптивная геологическая модель содержит столько слоев, сколько выделено путем детальной корреляции разреза. При этом каждый слой является единой подсистемой со своими закономерностями распределения в геологическом пространстве, и поэтому в его пределах можно корректно интерполировать. В процессе создания адаптивной геологической модели обычные методы интерполяции не применяются. Все геологические параметры слоя восстанавливаются по функциональным зависимостям от набора структурных поверхностей, построенных по сейсмическим данным. Для этого нужно иметь как минимум три таких поверхности.

Из-за невозможности подобрать одну функцию для всего рассматриваемого объекта формируется поле таких функций, иначе говоря, fuzzy-грид, который позволяет более гибко 
моделировать строение залежи и еe свойства. Fuzzy-грид - это однослойная редкая сетка с шагом 250 - 500 м, в узлах которой содержатся не геологические параметры, а много параметрические нечетко-логические функции, связывающие геологические параметры с вектором сейсмических параметров. Для расчета каждого геологического параметра формируется свой fuzzy-грид. Набор fuzzy-гридов составляет скелет геологической модели.

Созданная адаптивная геологическая модель пермо-карбоновой залежи Усинского месторождения содержит около 3 млн. ячеек, т.е. ее сетка пригодна для расчета гидродинамической модели без какого-либо апскейлинга.

Существуют два равнозначных подхода к расчету гидродинамических моделей. При использовании традиционного подхода на основе дифференциальных уравнений в частных производных подразумевается, что пласт непрерывный. При альтернативном подходе, основанном на теории перколяции и клеточных автоматов, моделируются перемещения дискретных объемов флюидов между ячейками в дискретный отрезок времени. Преимущество адаптивной гидродинамической модели заключается в том, что при ее расчете не возникает погрешности дискретизации, потому что эта модель не основана на дифференциальных уравнениях. Она в принципе дискретная. Не столь важными для адаптивной гидродинамической модели оказываются и абсолютные значения фильтрационных параметров пласта. В каждый момент времени для каждой ячейки имеет значение только относительные значения этих параметров между соседними ячейками. И самое главное, что адаптивную гидродинамическую модель не нужно настраивать на факт - она всегда настроена на факт по добыче нефти и воды. Основное предназначение адаптивной гидродинамической модели заключается в том, чтобы определить из каких зон пласта наиболее вероятно пришли отобранные в скважине флюиды и куда пошли закачиваемые рабочие агенты, повышая давление и обводненность пласта, и где уменьшились текущие запасы углеводородов.

Если для детерминированной гидродинамической модели в целях прогноза достаточно задать дебиты жидкости или депрессии, и она сама определит сколько в этой жидкости будет нефти, то для адаптивной гидродинамической модели необходимо задать конкретные отборы флюидов. Поэтому прогнозной расчет адаптивной гидродинамической модели выполняется в два этапа. Первый этап имеет непосредственную связь с характеристиками вытеснения, при помощи которых прогнозируется падение дебитов флюидов. По мере отбора дебит должен уменьшаться хотя бы потому, что флюидов стало меньше в пласте. На втором этапе расчета полученные отборы корректируются на основании статистических зависимостей о взаимовлиянии скважин. Это реализуется через систему уравнений интерференции скважин, основной смысл которой состоит в том, что на работу любой скважины влияет то, как работают окрестные добывающие и нагнетательные скважины и в то же время как она сама влияет на эти же окрестные скважины.

Расчет адаптивной гидродинамической модели пермо-карбоновой залежи Усинского месторождения с 1200 эксплуатационных скважин, имеющих практически 40 лет фактической истории, идет 6 - 8 часов на 8-ядерном компьютере. Прогноз на 30 лет для такой модели занимает 4 - 6 часов. В результате были получены прогноз уровней добычи нефти и распределения текущих запасов нефти в пласте.

На основе НАП можно прогнозировать дебиты и обводненность скважин после проведения на них ГТМ или автоматически подбирать скважины для ГТМ. Для этого нужно иметь статистический базис из набора ранее проведенных ГТМ с известным результатом. Для расчета используется матрица из практически 900 входных параметров, описывающих состояние скважины перед проведением ГТМ. Из них система сама отбирает порядка 20 наиболее значимых параметров по принципу «минимакса» (максимальная корреляция с целевым параметров и минимальная корреляция между собой).

Как показал опыт тестирования НАП на разных объектах «работают» разные параметры, но нет таких, которые работали бы везде и которые нигде бы не работали. При этом надо 
понимать, что НАП как статистический метод прогноза дает и статистический результат, т.е. нельзя точно предсказать дебит отдельно взятой скважины, но можно уверенно разделить любую группу скважин, на которых может быть проведен какой-либо вид ГТМ, на две части лучшую и худшую.

На рисунке 1 представлены результаты тестирования прогноза 535 ГТМ для условий пермокарбоновой залежи Усинского месторождения. Средний фактический дебит нефти всей выборки составляет 7.2 т/сут (синяя линия). Если отсортировать выборку по прогнозным дебитам нефти (красная линия) и взять лучшую правую половину, то ее средний фактический дебит нефти составит уже 10.3 т/сут, что в 1,3 раза больше чем средний фактический дебит нефти для всех выполненных ГТМ. Однако, как видно на рисунке 1, в лучшей половине также есть и неудачные скважины, а в худшей половине есть и хорошие скважины. Вместе с тем, всегда есть выигрыш по среднему дебиту и это является устойчивым.

Еще одним объектом применения НАП стало месторождение Северные Бузачи, которое расположено в Прикаспийской нефтегазоносной провинции, имеет крупные запасы аномально вязкой нефти $(300-400$ мПа*c) в неглубокозалегающих терригенных пластах юрских и меловых отложений. При помощи НАП были созданы и рассчитаны адаптивные геологогидродинамические модели обоих объектов, что позволило получить карты плотности начальных и текущих запасов нефти, а также распределения отобранной из объектов нефти. Для тестирования созданных моделей вычислялись прогнозные уровни добычи нефти и жидкости. Далее определялись коэффициенты корреляции расчетных и фактических дебитов на каждый прогнозный месяц. Из полученных данных следует, что относительно хорошая корреляция факта и прогноза наблюдается в первые три месяца (более 70 \%). До шести месяцев корреляция остается удовлетворительной, но ошибки начинают быстро возрастать. С использованием адаптивных гидродинамических моделей удалось также рассчитать дебиты такого вида ГТМ как бурение новых скважин. На рисунке 2 представлены результаты выполненного расчета как для юрских, так и для меловых отложений в виде карт перспективности бурения новых скважин (наиболее перспективные зоны показаны в красножелтых тонах). Прогнозные дебиты нефти целесообразно рассматривать в качестве дополнительного аргумента при выборе точек заложения новых скважин.

Адаптивные гидродинамические модели позволяют использовать в качестве исходных данных не только фактические показатели, но и результаты детерминированного моделирования. Основная идея при этом заключается в том, чтобы с помощью секторных детерминированных моделей рассчитать несколько вариантов дальнейшей разработки актуальных участков на основе различных МУН, например, закачки горячей воды с различной температурой и влажного насыщенного пара, а затем, используя выявленные закономерности, спрогнозировать показатели разработки рассматриваемого объекта в целом при помощи его адаптивной гидродинамической модели.

Построенные адаптивные модели показали свою работоспособность для условий как пермокарбоновой залежи Усинского месторождения, так и месторождения Северные Бузачи. Эти модели не являются упрощенными, они сложные и требуют практически столько же расчетного времени, как и детерминированные модели. Однако адаптивные модели проще для пользователей, поскольку не требуют никакой ручной работы и всегда настроены на факт, поэтому в итоге оказываются дешевле и быстрее детерминированных. Применение НАП в дополнение к другим способам прогнозирования позволяет проводить перекрестную проверку результатов и тем самым снизить вероятность появления ошибок и повысить качество принимаемых решений, которые в случае с ГТМ и МУН очень часто оказываются весьма дорогостоящими. В результате систематического применения методики адаптивного прогнозирования состояния месторождений и залежей можно повысить эффективность их разработки как минимум на $10,0-15,0 \%$. 


\section{EAGE}

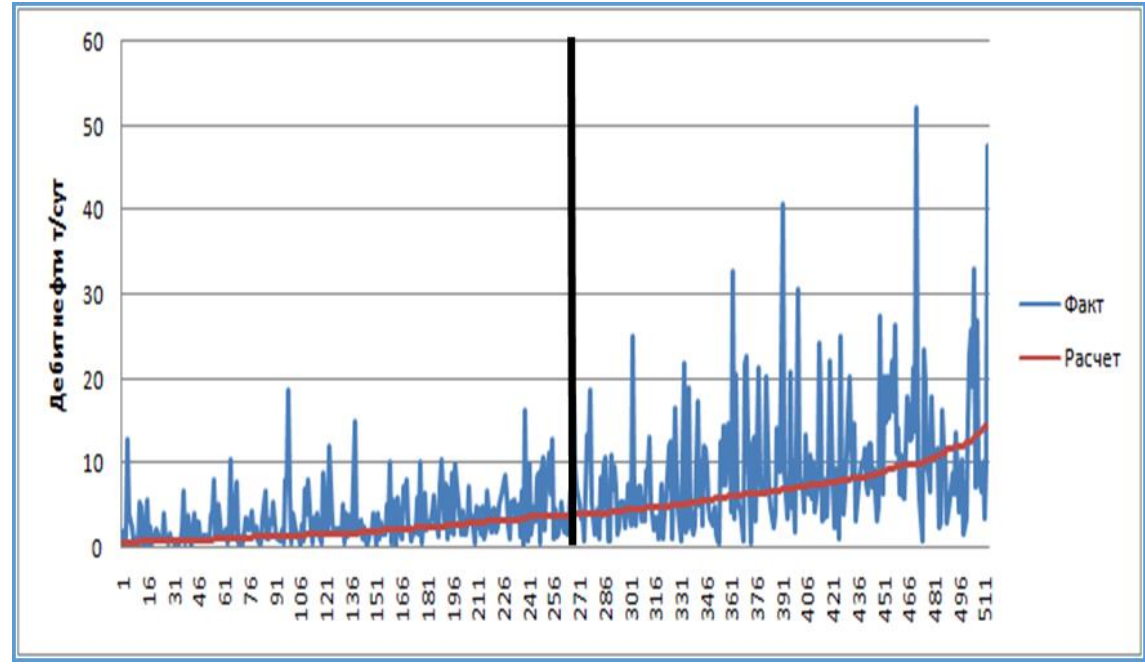

Рисунок 1.Результаты прогнозирования эффективности проведения ГТМ на пермо-карбоновой залежи Усинского месторождения.
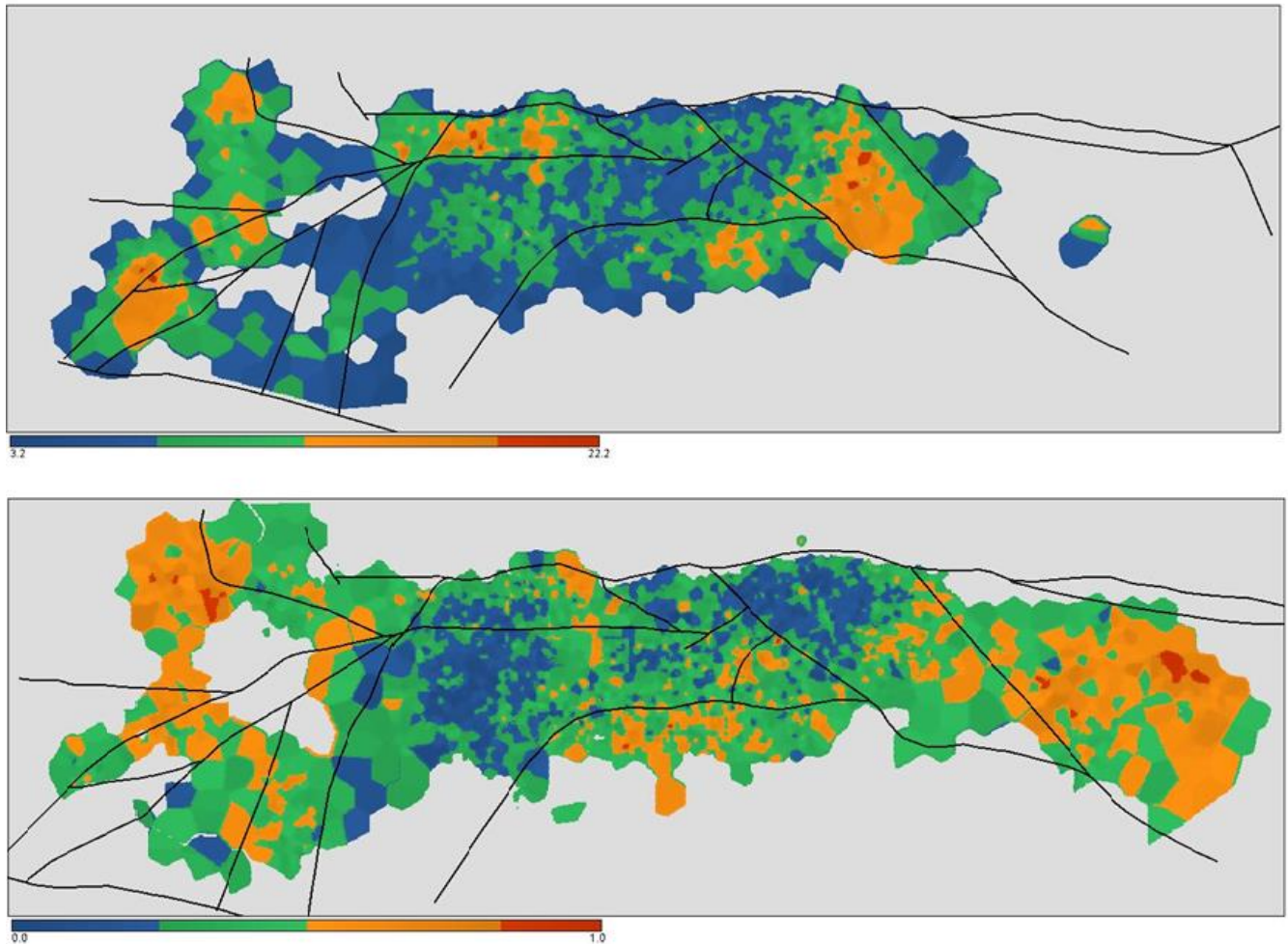

Рисунок 2. Прогнозирование эффективности бурения новых скважин на месторождении Северные Бузачи (A - юрские отложения, Б- меловые отложения).

\section{Литература}

1. Эшби У.Р. Введение в кибернетику. - М.: Иностранная литература, 1959. - 432 с.

2. Мирзаджанзаде А.Х., Хасанов М.М., Бахтизин Р.Н. Этюды о моделировании сложных систем нефтедобычи. - Уфа: Гилем, 1999. - 464 с.

3. Duda R.O., Hart P.E., Stork D.G. Pattern Classification, 2nd ed., Wiley-Interscience, New York, 2000. $-637 \mathrm{p}$. 


\section{EAGE}

EUROPEAN

ASSOCIATION OF

GEOSCIENTISTS
ENGINEERS

\section{References}

1. Ashby W.R. Introduction to Cybernetics. - M.: Inostrannay literatura, 1959. - 432 p.

2. Mirzadzhanzade A.K., Khasanov M.M., Bakhtizin R.N. Etudes on complex oil production systems' modeling. - Ufa: Gilem, 1999. - 464 p.

3. Duda R.O., Hart P.E., Stork D.G. Pattern Classification, 2nd ed., Wiley-Interscience, New York, 2000. $-637 \mathrm{p}$. 